\title{
Million Organisms per Milliliter
}

National Cancer Institute

\section{Source}

National Cancer Institute. Million Organisms per Milliliter. NCI Thesaurus. Code C71196.

A unit of measure of organism concentration expressed in millions of org anisms per unit of volume equal to one milliliter. 